\title{
The effect of local muscle vibration on clinical and biomechanical parameters in people with knee osteoarthritis: A systematic review
}

\author{
Kourosh Barati ${ }^{1,2}$, Elham Esfandiari ${ }^{3}$, Mojtaba Kamyab ${ }^{1}$, Ismail Ebrahimi Takamjani ${ }^{4} * \mathbb{D}$, Rasha Atlasi ${ }^{5}$, \\ Mohammad Parnianpour ${ }^{6}$, Hamidreza Yazdi ${ }^{7}$, Shabnam Shahali ${ }^{4}$, Shahrbanoo Bidari ${ }^{1}$ \\ Received: 19 Oct 2020 \\ Published: 27 Sep 2021
}

\begin{abstract}
Background: To identify and synthesize available published studies on the effect of local muscle vibration (LMV) on pain, stiffness, and function in individuals with knee OA.

Methods: Five databases were searched to find relevant papers on April 29, 2020, including, PubMed, Scopus, EMBASE (Ovid), Science Citation Index, and COCHRANE Central Register for Controlled Trials (CENTRAL). Randomized controlled trials (RCTs) and nonrandomized-controlled-trials (non-RCTs), such as interrupted time series and prospective cohort studies were included. Two independent reviewers screened articles and assessed inclusion through predefined criteria. Participants' characteristics, study design, intervention characteristics, outcomes, and main results were collected independently by 2 reviewers. 'The risk of bias assessment of included studies was conducted using Cochrane risk of bias tools for RCTs and non-RCTs.

Results: Six studies were included: 3 RCTs and 3 non-RCTs. The risk of bias in included studies was generally moderate to high. Improvement of pain, stiffness, and function following the application of LMV were reported in all studies.

Conclusion: This review revealed the promising effect of LMV on pain, stiffness, function, and knee range of motion (ROM) improvements for individuals with knee Osteoarthritis $(\mathrm{OA})$. However, further well-designed studies are required to have a convincing conclusion on the effect of LMV in individuals with knee OA.
\end{abstract}

Keywords: Knee Osteoarthritis, Local Muscle Vibration, Pain

Conflicts of Interest: None declared

Funding: This study was financially supported by Iran University of Medical Sciences (Grant No. 97-4-6-13280) and the Iranian Naitional Science Foundation (Grant No. 96012163).

\section{*This work has been published under CC BY-NC-SA 1.0 license.}

Copyright $₫$ Iran University of Medical Sciences

Cite this article as: Barati K, Esfandiari E, Kamyab M, Ebrahimi Takamjani I, Atlasi R, Parnianpour M, Yazdi H, Shahali Sh, Bidari Sh. The effect of local muscle vibration on clinical and biomechanical parameters in people with knee osteoarthritis: A systematic review. Med J Islam Repub Iran. 2021 (27 Sep);35:124. https://doi.org/10.47176/mjiri.35.124

\section{Introduction}

Osteoarthritis (OA) is one of the most common knee joint degenerative diseases (1). The prevalence of knee
OA in the United States was estimated to be 27 million in 2005 and is expected to be 67 million in $2030(2,3)$. The
Corresponding author: Dr Ismail Ebrahimi Takamjani, Ebrahimitakamjani.e@iums.ac.ir

${ }^{1 .}$ Rehabilitation Research Centre, Department of Orthotics \& Prosthetics, School of Rehabilitation Sciences, Iran University of Medical Sciences, Tehran, Iran

2. Department of Orthotics \& Prosthetics, School of Rehabilitation Sciences, Shiraz University of Medical Sciences, Shiraz, Iran

3. University of British Columbia, Vancouver, BC, Canada

4. Rehabilitation Research Centre, Department Physiotherapy, School of Rehabilitation Sciences, Iran University of Medical Sciences, Tehran, Iran

5. Endocrinology \& Metabolism Clinical Sciences Institute, Evidence-Based Practices Resource Center ,Tehran University of Medical Sciences, Tehran, Iran

6. Department of Orthopedics, School of Medicine, Iran University of Medical Sciences, Tehran, Iran

7. Department of Mechanics, Sharif University of Technology, Tehran, Iran $\uparrow$ What is "already known" in this topic:

Knee osteoarthritis is associated with pain, joint stiffness, functional disability, and loss of knee joint range of motion. The application of local muscle vibration is reported to be effective on biomechanical parameters in asymptomatic healthy people. However, there is contradictory evidence on the effect of local muscle vibration on clinical and biomechanical parameters in individuals with knee OA.

\section{$\rightarrow$ What this article adds:}

The results of this study showed that the application of local muscle vibration improves paiin, stiffness, function, and knee ROM in people with knee osteoarthritis. However, further well-designed studies are required to have a convincing conclusion on the effect of local muscle vibration in people with knee osteoarthritis. 
knee OA causes pain, stiffness, functional disability, loss of knee joint range of motion (ROM), and decreased quadriceps muscle activity $(4,5)$.

The conservative treatments for rehabilitation of individuals with knee OA consist of weight loss, patient education on coping strategies, exercises, orthotic treatments, and neuromuscular training (6). Neuromuscular training, such as whole-body vibration (WBV) and local muscle vibration (LMV), have been suggested over the past 2 decades to improve muscular activity and functional capacity in knee OA (7-10). The WBV is the most commonly used method and is reported to be effective in the management of complications of knee OA $(7,9,11)$. However, a decrease in vibration energy before attaining the target muscle, the high cost of associated equipment, and the limited portability of the WBV platform, are reasons to limit its application in clinical settings $(12,13)$. The LMV is a method of neuromuscular training that could be directly applied to the targeted muscle belly or muscle-tendon via a lightweight handheld applicator and might be considered as a cost-effective alternative for WBV.

According to the International Classification of Functioning, Disability, and Health (ICF) (14), the main aim of rehabilitation of individuals with knee $\mathrm{OA}$ is to decrease the level of disability by improving 'body function' and 'activity and participation components' Body function is defined as what an individual can do in a standard environment. Additionally, activity is the execution of a task by an individual, and participation is contribution and involvement in a life situation (15). To encompass all aspects of disability, it may be necessary to employ outcome measures in the 2 components. Pain is the most common consequence of knee OA (16) and is associated with increased joint stiffness, decreased knee ROM (17), and decreased muscle function (18). All of these complications are associated with a decrease in physical function (19-21). As a result, these outcomes should be assessed as the main outcomes following intervention in the rehabilitation of individuals with knee OA. In most studies, vibration has been applied in sitting positions (22-26). However, the application of LMV in standing and walking positions has recently been suggested (27). To decide on the application of the LMV in the standing and walking conditions for the rehabilitation of individuals with knee OA, it must be ensured that it does not adversely affect the postural control.

The effect of LMV on biomechanical parameters, such as peak torque, muscle function, and muscle strength, was reported in asymptomatic healthy individuals (13, 27-34). One systematic review synthesized the effect of LMV on muscle strength in asymptomatic healthy individuals (10) and showed that LMV could enhance muscle strength. However, there is contradictory evidence on the effect of LMV on clinical and biomechanical parameters in individuals with knee $\mathrm{OA}(22,23,25,26)$. For example, Benedetti et al showed that the application of LMV for 2 weeks would increase the muscular activity in individuals with knee OA. However, Rice et al (26) reported no statistically significant change in the produced torque and quadriceps and hamstring muscle strength.
Therefore, we conducted a systematic review of the peer-reviewed publications to identify and synthesize the available peer-reviewed publications on the effect of LMV on knee joint pain, stiffness, physical function, postural balance, and muscular activity in individuals with knee OA. In addition, we aimed to identify the most important LMV characteristics, such as frequency, the amplitude of displacement, application location, and position of the application.

\section{Methods}

\section{Protocol and Registration}

The protocol of this systematic review has been formerly issued in PROSPERO with registration No. CRD42019116321. The PRISMA (Preferred Reporting Items for Systematic reviews and Meta-Analyses) guidelines were followed to perform the current review (35).

\section{Eligibility Criteria}

The published studies with the following criteria were included in our review: population: individuals with knee OA, grade II to III based on the Kellgren and Lawrence (K\&L) grading system (36), aged between 35 to 75 years; intervention: LMV, which was the local application of vibration to the muscle belly or the tendon via an applicator; comparator: fake vibration, exercise, and no treatment; outcomes: pain, stiffness, and function, ROM, electromyography (EMG), and postural response; study designs: randomized controlled trials (RCTs), interrupted time series, and prospective cohort studies. Studies that evaluated the effect of WBV were excluded.

\section{Information Sources}

Five databases were searched to find relevant papers on April 29, 2020, including, PubMed, EMBASE (Ovid), Scopus, Science Citation Index, and COCHRANE Central Register for Controlled Trials (CENTRAL). We conducted a manual search of Google scholar with "Allintitle" to find more papers that are relevant. The registry of clinical trials (clinical trials.gov), and the World Health Organization (15) international clinical trials registry platform (http://www.who.int/ictrp/en/) were searched to ascertain the comprehensiveness of the search. First, the first author searched the PubMed database to develop a search template using key concepts, Medical Subject Headings (MeSH) terms, and keywords. Then, the second author checked the template for comprehensiveness. The search template was used to complete the searches in the remaining databases. We searched the reference list of included papers to find more papers that are relevant. The search was limited to the English language.

\section{Search}

The search strategy used for the PubMed search is presented in Table 1. This search strategy was used as a template to do the searches in the remaining databases.

\section{Study Selection}

Two independent reviewers (first and second authors) screened the titles and abstracts at screening level 1 . The 
Table 1. Search Strategies

\begin{tabular}{|c|c|c|}
\hline Databases & $\begin{array}{l}\text { Total Found } \\
\text { Articles }\end{array}$ & Search \\
\hline PubMed & 100 & $\begin{array}{l}\text { ("Vibration"[Mesh] OR Vibrat*[TIAB] ) AND ("Osteoarthritis, Knee"[Mesh] OR (("Knee Joint"[Mesh] OR } \\
\text { "Knee"[Mesh] OR Knee[TIAB] OR Knees[TIAB] OR femorotibial[TIAB]) AND ("Osteoarthritis"[Mesh] } \\
\text { OR Osteoarth*[TIAB] OR arthros*[TIAB] OR "Arthritis"[Mesh] OR arthrit*[TIAB] OR osteo- } \\
\text { arthritis[TIAB] OR osteo-arthrosis[TIAB])) OR gonarthrosis[TIAB]) }\end{array}$ \\
\hline Scopus & 157 & $\begin{array}{l}\text { TITLE-ABS-KEY((Vibrat* ) AND (((Knee OR Knees OR femorotibial) AND (Osteoarth* OR arthros* OR } \\
\text { arthrit* OR osteo-arthritis OR osteo-arthrosis) ) OR gonarthrosis) ) }\end{array}$ \\
\hline Web of Science & 176 & $\begin{array}{l}\text { TS }=((\text { Vibrat* }) \text { AND }(((\text { Knee OR Knees OR femorotibial) AND (Osteoarth* OR arthros* OR arthrit* OR } \\
\text { osteo-arthritis OR osteo-arthrosis })) \text { OR gonarthrosis }))\end{array}$ \\
\hline EMBASE & 194 & $\begin{array}{l}\text { (Vibrat*:ab,ti OR 'vibration'/exp ) AND ('knee osteoarthritis'/exp OR (('knee'/exp OR Knee:ab,ti OR } \\
\text { Knees:ab,ti OR femorotibial:ab,ti) AND ('osteoarthritis'/exp OR 'arthritis'/exp OR Osteoarth*:ab,ti OR ar- } \\
\text { thros*:ab,ti OR arthrit*:ab,ti OR osteo-arthritis:ab,ti OR osteo-arthrosis:ab,ti)) OR gonarthrosis:ab,ti) }\end{array}$ \\
\hline
\end{tabular}

third reviewer adjudicated any unresolved discrepancies. Then, 2 reviewers screened the full-texts (level 2). The reason for the exclusion of the papers was recorded.

\section{Data Collection Process}

The data extraction was conducted by the first author and the second author reviewed the accuracy of the data. The missing records were requested from the corresponding author with email contact. If we received no response, the author was contacted twice, at 1-week intervals.

\section{Data Extraction}

The following information was extracted from each study. The first author, publication year, the country in which the study was conducted, study design, objectives, primary and secondary outcome measures, the main results, and conclusions, participants' characteristics (knee OA grade, number of samples, sex, and mean age), and vibration characteristics (frequency, amplitude of displacement, force, location of LMV application, and duration of LMV application).

\section{Risk of Bias in Individual Studies}

Two independent reviewers (first and second authors) performed the risk of bias assessment of the included studies. The disagreements among the reviewers were resolved by discussion with the third reviewer to reach a consensus.
The risk of bias in RCTs was assessed using the Cochrane Risk of Bias (RoB 2.0) tool (37). This tool consisted of 5 domains: randomization process, deviations from intended interventions, missing outcome data, measurement of outcomes, and selection of the reported result. Three judgments were possible for risk of bias: low, some concerns, and high. A summary of bias assessment of included randomized studies is provided in Table 2.

The nonrandomized studies were assessed using the Cochrane Risk Of Bias In Non-randomized Studies-of Interventions (ROBINS-I) tool (38). This tool consisted of 7 domains: confounding, selection of participants into the study, classification of the interventions, deviations from intended interventions, missing data, measurement of outcomes, and selection of the reported result. Five judgments were possible for risk of bias: no information, low, moderate, serious, or critical. A summary of bias assessment of included nonrandomized studies is provided in Table 3 .

\section{Synthesis of Results}

We planned to conduct a meta-analysis if data were available. If pooling of data was not possible because of methodological heterogeneity (variability in trial design and quality) or clinical heterogeneity (variability in participants and intervention type) among studies (39), we planned to conduct a narrative synthesis of the findings.

Table 2. Risk of Bias Assessment for Randomized Controlled Studies Using the Cochrane Risk of Bias (RoB 2.0) Tool

\begin{tabular}{|c|c|c|c|c|c|c|}
\hline $\begin{array}{l}\text { Study } \\
\text { (Year) }\end{array}$ & $\begin{array}{c}\text { Randomization } \\
\text { Process } \\
\end{array}$ & $\begin{array}{l}\text { Deviations From In- } \\
\text { tended Interventions }\end{array}$ & $\begin{array}{l}\text { Missing Out- } \\
\text { come Data }\end{array}$ & $\begin{array}{c}\text { Measurement } \\
\text { of Outcomes }\end{array}$ & $\begin{array}{l}\text { Selection of the } \\
\text { Reported Result }\end{array}$ & Overall \\
\hline Benedetti et al & Low risk & Some concerns & Some concerns & Low risk & Some concerns & Some concerns \\
\hline Rabini et al & Low risk & Low risk & Low risk & Low risk & Some concerns & Some concerns \\
\hline Kitay et al & Low risk & High risk & Some concerns & Low risk & Some concerns & High risk \\
\hline
\end{tabular}

Table 3. Risk of Bias Assessment for Nonrandomized Studies Using the Cochrane Risk of Bias in Nonrandomized Studies of Interventions tool

\begin{tabular}{|c|c|c|c|c|c|c|c|c|}
\hline $\begin{array}{l}\text { Study } \\
\text { (Year) }\end{array}$ & Confounding & $\begin{array}{l}\text { Selection of } \\
\text { Participants } \\
\text { into the } \\
\text { Study }\end{array}$ & $\begin{array}{l}\text { Classification } \\
\text { of the Inter- } \\
\text { ventions }\end{array}$ & $\begin{array}{c}\text { Deviations } \\
\text { From Intended } \\
\text { Interventions }\end{array}$ & $\begin{array}{c}\text { Missing } \\
\text { Data }\end{array}$ & $\begin{array}{l}\text { Measure- } \\
\text { ment of } \\
\text { Outcomes }\end{array}$ & $\begin{array}{c}\text { Selection of } \\
\text { the } \\
\text { Reported } \\
\text { Result }\end{array}$ & Overall \\
\hline Rice et al & Serious & Low & Low & Low & Low & Moderate & Low & Serious \\
\hline Shanahan et al & Low & Low & Low & Low & Low & Moderate & Low & Moderate \\
\hline Lievens et al & Low & Low & Serious & Low & Low & Serious & Low & Serious \\
\hline
\end{tabular}




\section{Results}

Study Selection

A total of 676 studies were identified through 5 electronic databases (Fig. 1). After removing duplicates and review of titles and abstracts, 27 studies were considered eligible to be included in the full-text screening. Of these, 21 studies were excluded: 3 studies were not available in English, 7 used different interventions, 7 were conference abstracts, 2 used different populations, and 2 records were clinical trial registrations. No study was identified in a manual search of reference lists. Finally, 6 studies were included in the review.

\section{Study Characteristics}

The studies were conducted Australia (24), Belgium (40), Italy (22, 23), New Zealand (26), and United States (25). The sample size ranged from 8 to 71 , with a mean age of 58.6 to 74.4 years (Table 4 ). Table 4 details the characteristics of participants.

Four studies included individuals with knee OA $(22,23$, $25,40)$, and 2 included 2 groups of healthy asymptomatic individuals and individuals with knee OA $(24,26)$. Also, 4 studies included established knee OA ( $\geq 2$ based on the K\&L grading system) (23-26), and 2 studies did not report knee OA grade $(22,40)$.

The characteristics of LMV (frequency, displacement amplitude, force, duration, and location of application) used in the studies are summarized in Table 4. The setups of LMV were different; the amplitude and frequency of the LMV were 0.1 (25) to $1.5 \mathrm{~mm}$ (26) and $10(25)$ to 150 $\mathrm{Hz}$ (22), respectively. The LMV application time was 15 seconds (24) to 20 minutes $(22,25,26,40)$. The application of LMV was on the muscles' belly $(22,24)$, on the infra-patellar tendon $(23,26)$, and the knee joint $(25,40)$. The force of LMV was reported to be 20 (22) to $30 \mathrm{New}-$ ton (26). The force was not reported in 4 studies (23-25, 40).

\section{Risk of Bias in Individual Studies}

Based on the RoB 2 Tool, one of the RCTs was at high risk of bias. Based on the Robins-I tool, 2 non-randomized studies were at serious risk of bias.

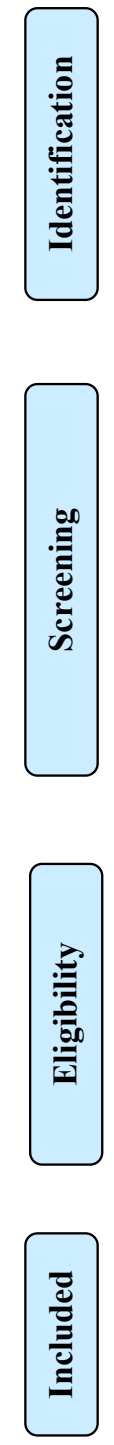

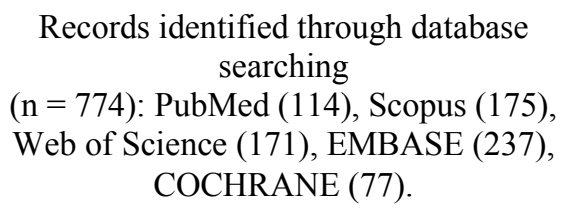

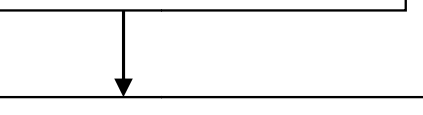

Records after duplicates removed

$$
(\mathrm{n}=367)
$$

Additional records identified through other sources $(\mathrm{n}=0)$
Records excluded $(\mathrm{n}=380)$

Fig. 1. The PRISMA (Preferred Reporting Items for Systematic Reviews and Meta-Analyses flow diagram) 
Table 4. Overview of the Studies Concerning the Effect of Local Muscle Vibration in Patients With Knee Osteoarthritis. Description of Interventions in Included Studies

\begin{tabular}{|c|c|c|c|c|c|c|}
\hline Author/ & Mean age & Participants & Control Interven- & & Vibration Protocol & \\
\hline $\begin{array}{l}\text { Year/ } \\
\text { Country }\end{array}$ & (years) & & tion & $\begin{array}{l}\text { Vibration } \\
\text { Parameters }\end{array}$ & $\begin{array}{l}\text { Location of Vibra- } \\
\text { tion Application }\end{array}$ & $\begin{array}{l}\text { Duration of Vibra- } \\
\text { tion Application }\end{array}$ \\
\hline $\begin{array}{l}\text { Benedetti et } \\
\text { al. } 2017, \\
\text { Italy }\end{array}$ & 58.6 & $\begin{array}{l}\text { - Knee OA participants in } \\
\text { the intervention group } \\
\qquad(\mathrm{n}=15) \\
\text { - Knee OA participants in } \\
\text { the control group }(\mathrm{n}=15)\end{array}$ & NMES application & $\begin{array}{c}\mathrm{F}=150 \mathrm{~Hz} \\
\mathrm{~A}=\mathrm{N}-\mathrm{m} \\
\text { Force }=20-25 \mathrm{~N}\end{array}$ & $\begin{array}{l}\text { - Vastus latteralis } \\
\text { muscle belly } \\
\text { - Vastus medialis } \\
\text { muscle belly } \\
\text { - Rectus femoris } \\
\text { muscle belly }\end{array}$ & $\begin{array}{l}2 \text { weeks, } \\
5 \text { days per week, } \\
1 \text { time each day, } \\
20 \text { min each time. }\end{array}$ \\
\hline $\begin{array}{l}\text { Rabini et al. } \\
2015 \text {, Italy }\end{array}$ & 74.4 & $\begin{array}{l}\text { - Knee OA participants in } \\
\text { the intervention group } \\
\qquad(n=25) \\
\text { - Knee OA participants in } \\
\text { the control group }(n=25)\end{array}$ & Sham treatment & $\begin{array}{c}\mathrm{F}=100 \mathrm{~Hz} \\
\mathrm{~A}=0.2 \text { to } 0.5 \\
\mathrm{~mm} \\
\text { Force }=\mathrm{N}-\mathrm{m}\end{array}$ & $\begin{array}{l}\text { Close to infra- } \\
\text { patellar tendon }\end{array}$ & $\begin{array}{l}3 \text { consecutive days, } \\
3 \text { times each day, } \\
10 \text { min each time, } \\
1 \text { min interruption. }\end{array}$ \\
\hline $\begin{array}{l}\text { Shanahan et } \\
\text { al. } 2014 \text {, } \\
\text { Australia }\end{array}$ & 66 & $\begin{array}{l}\text { - Knee OA participants } \\
\text { treated with LMV }(\mathrm{n}=30) \\
\text { - Health group treated } \\
\text { with LMV }(\mathrm{n}=30)\end{array}$ & $\begin{array}{l}\text { Pre/ post vibration } \\
\text { application }\end{array}$ & $\begin{array}{c}\mathrm{F}=60 \mathrm{~Hz} \\
\mathrm{~A}=0.5 \mathrm{~mm} \\
\text { Force }=\mathrm{N}-\mathrm{m}\end{array}$ & $\begin{array}{c}\text { - Quadriceps muscle } \\
\text { belly. } \\
\text { - Triceps surae } \\
\text { tendon. } \\
\text { - Tibialis anterior } \\
\text { muscle belly. }\end{array}$ & $\begin{array}{c}1 \text { day, } \\
2 \text { times each day, } \\
15 \mathrm{~s} \text { each time. }\end{array}$ \\
\hline $\begin{array}{l}\text { Rice et al. } \\
\text { 2011, New } \\
\text { Zealand }\end{array}$ & 62.7 & $\begin{array}{l}\text { - Knee OA participants } \\
\text { treated with LMV }(\mathrm{n}=15) \\
\text { - Health group treated } \\
\text { with LMV }(\mathrm{n}=15)\end{array}$ & $\begin{array}{l}\text { Pre/ post vibration } \\
\text { application }\end{array}$ & $\begin{array}{c}\mathrm{F}=50 \mathrm{~Hz} \\
\mathrm{~A}=1.5 \mathrm{~mm} \\
\text { Force }=25-30 \mathrm{~N}\end{array}$ & Infrapatellar tendon. & $\begin{array}{l}1 \text { day, } \\
1 \text { time each day, } \\
20 \text { min each time. }\end{array}$ \\
\hline $\begin{array}{l}\text { Kitay et al. } \\
2009 \text {, Unit- } \\
\text { ed States }\end{array}$ & 61.4 & $\begin{array}{l}\text { - Knee OA participants in } \\
\text { the intervention group } \\
\qquad(n=34) \\
\text { - Knee OA participants in } \\
\text { the control group }(n=37)\end{array}$ & Sham treatment & $\begin{array}{c}\mathrm{F}=10 \mathrm{~Hz}, 27 \\
\mathrm{~Hz}, 42 \mathrm{~Hz} \\
\mathrm{~A}=0.1 \mathrm{~mm} \\
\text { Force }=\mathrm{N}-\mathrm{m}\end{array}$ & $\begin{array}{l}\text { - Just above the knee } \\
\text { joint. } \\
\text { - Just below the } \\
\text { knee joint. }\end{array}$ & $\begin{array}{l}4 \text { weeks, } \\
7 \text { days each week, } \\
2 \text { times each day, } \\
20 \text { min each time. }\end{array}$ \\
\hline $\begin{array}{l}\text { Lievens et } \\
\text { al. } 1984, \\
\text { Belgium }\end{array}$ & $\mathrm{N}-\mathrm{m}$ & $\begin{array}{l}\text { - Knee OA participants in } \\
\text { the intervention group } \\
\qquad(\mathrm{n}=8) \\
\text { - Knee OA participants in } \\
\text { the control group }(\mathrm{n}=8)\end{array}$ & No-treatment & $\begin{array}{c}\mathrm{F}=\mathrm{N}-\mathrm{m} \\
\mathrm{A}=.5-1 \mathrm{~mm} \\
\text { Force }=\mathrm{N}-\mathrm{m}\end{array}$ & Just above the knee. & $\begin{array}{c}10 \text { days, } \\
1 \text { time each day, } \\
20 \text { min each time. }\end{array}$ \\
\hline
\end{tabular}

The overall risk of bias assessment showed that the risk of bias was high (or serious) in 3 studies $(25,26,40)$; of the other 3 studies, $2(22,23)$ had a 'some concerns' risk of bias, and 1 (24) had a moderate risk of bias. In RCTs, the 'randomization process' and 'measurement of outcomes' domains were dominant with a low risk of bias (Table 2). In nonrandomized papers, the 'selection of participants into the study,' 'deviations from intended interventions,' and 'missing data' domains were dominant with a low risk of bias (Table 3). The most common shortcomings in RCTs and nonrandomized studies were the measurement of outcomes and selection of the reported result (Table 2 and Table 3).

\section{Results of Studies}

We reviewed the results of studies with respect to therapeutic and biomechanical outcomes: pain, stiffness, function, EMG, ROM, and postural response. A detailed summary of the study results is provided in Table 4 and Table 5.

\section{Pain}

Pain was reported in 3 studies $(22,23,25)$ using the Western Ontario and McMaster universities arthritis index (WOMAC). Two 'some concern quality' studies found that 3 consecutive days to the 2-week application of LMV improved pain in individuals with knee OA in comparison with individuals with knee OA who received sham treat- ment (23) or neuromuscular electrical stimulation (NMES) application (22). One 'high-risk quality' study also showed that a 4-week application of LMV improved pain in individuals with knee OA compared to individuals with knee OA who received sham treatment (25). The knee OA grade of participants was $\geq 2$ based on the K\&L grading system.

\section{Stiffness}

The effect of LMV on stiffness was assessed in 3 studies using the WOMAC index $(22,23,25)$. One 'some concern quality' study found that 3-day application of LMV improved stiffness in individuals with knee OA compared to individuals high-risk OA who received sham treatment (23). A similar finding was reported in a 'high risk quality' study which assessed the 4-week effect of LMV in individuals with knee OA (25). The stiffness score was not reported separately in 1 'some concern quality' study (22). However, the improvement of the WOMAC total score following a 2-week application of LMV in individuals with knee OA compared to individuals with knee OA who received NMES was reported. The knee OA grade of participants was $\geq 2$ based on the $\mathrm{K} \& \mathrm{~L}$ grading system (Table 4) $(22,23,25)$.

\section{Physical Function}

Change in physical function following application of LMV was investigated in 3 studies using the WOMAC 


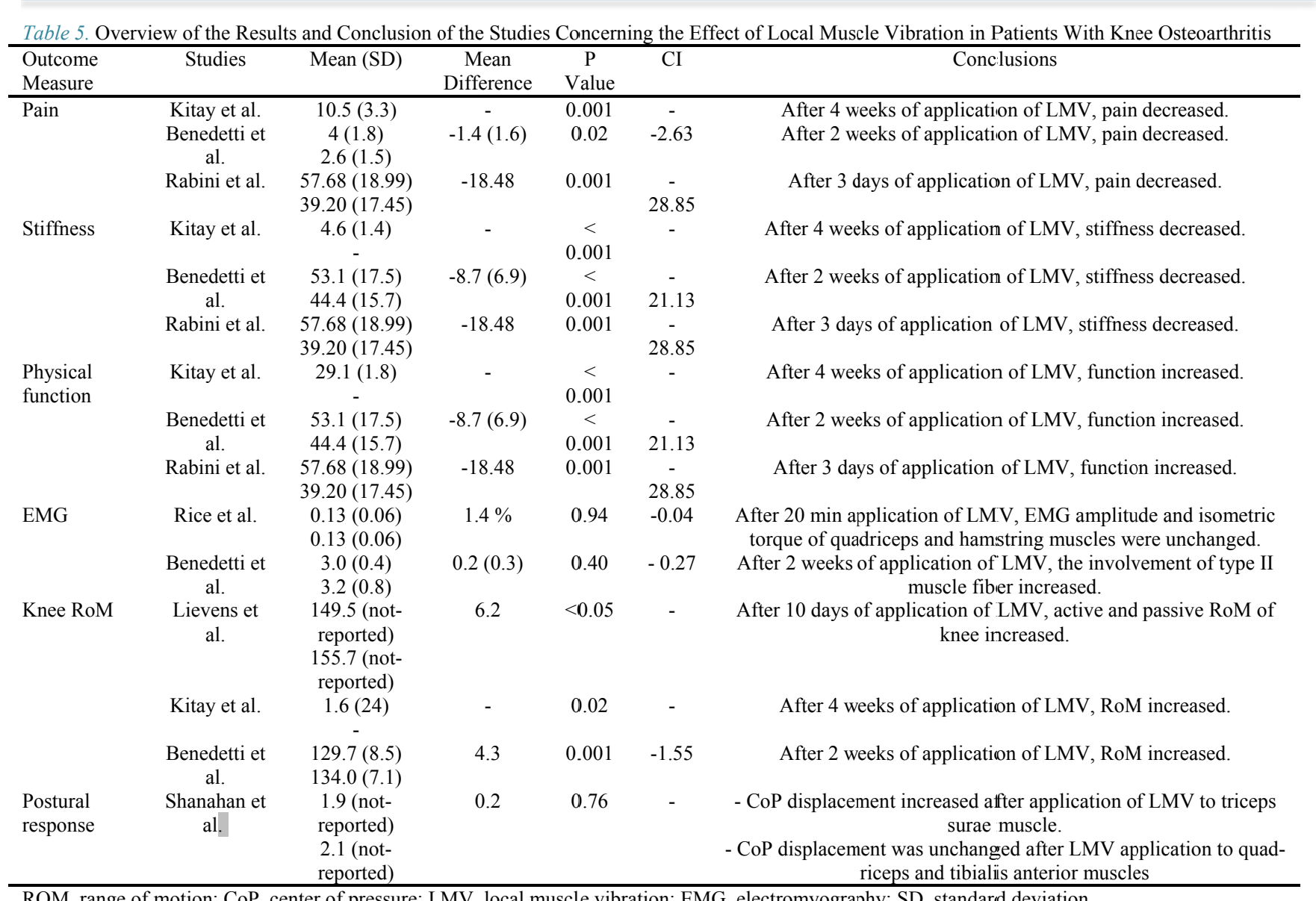

ROM, range of motion; CoP, center of pressure; LMV, local muscle vibration; EMG, electromyography; SD, standard deviation.

index $(22,23,25)$. One 'some concern quality' study on 3consecutive days of LMV application showed the improvement of physical function in individuals with knee OA compared to individuals high-risk OA who received sham treatment (23). Similar results were reported in a 'high risk quality' study with 4-weeks of LMV application (25). The physical function score was not reported separately in 1 'some concern quality' study (22). However, they reported improvement in the WOMAC total score following a 2-week application of LMV in individuals with knee OA compared to individuals with knee OA who received NMES. The knee OA grade of participants was $\geq 2$ based on the K\&L grading system.

\section{Electromyography}

One 'some-concern quality' study (22) (based on RoB 2.0 tool) and 1 'serious-risk quality' study (26) (based on ROBINS-I tool) evaluated the muscular activity of quadriceps and hamstrings muscles following application of LMV using EMG. Rice et al (26) reported that 1-day application of LMV (20 minutes) to infer-patellar tendon has no significant effect on the EMG amplitude of quadriceps muscle in individuals with knee OA compared to asymptomatic healthy individuals who received LMV. Benedetti et al (22) reported that 2-week application of LMV to vastus lateralis could lead to a decrease in mean frequency of the power spectrum and muscle fiber conduction veloc- ity of individuals with knee OA compared to individuals with knee OA who received NMES.

\section{Range of Motion}

One 'some-concern quality' (22), 1 'high-risk quality' study (25) (based on RoB 2.0 tool), and 1 'serious risk quality' study (40) (based on ROBINS-I tool) evaluated the effect of LMV on knee ROM in individuals with knee OA. Consistently across 3 studies, knee ROM was increased following the application of LMV. Application of LMV to quadriceps muscle belly induced an increase in knee ROM in individuals with knee OA compared to individuals with knee OA who received NMES (22). Application of LMV to surfaces above and below of the knee joint induced an increase in knee ROM in individuals with knee OA compared to individuals with knee OA who received sham treatment (25). Application of LMV to only 1 surface above the knee joint induced an increase in knee ROM in individuals with knee OA compared to individuals with knee OA who received no treatment (40). The duration of the intervention varied from 3 consecutive days ( 3 times each day) (22) to 10 days ( 1 time each day) (40), and 4 weeks (14 times each week) (25).

\section{Postural Response}

Only one 'moderate-risk quality' study evaluated the effect of LMV on postural control in individuals with knee 
OA using the displacement of the center of pressure (CoP) (24). The results suggested that anterior-posterior displacement of $\mathrm{CoP}$ had no change following 2-time (15 seconds each time) application of LMV to quadriceps and tibialis anterior muscles in individuals with knee OA compared to asymptomatic healthy individuals who received LMV. However, the application of LMV on triceps surae would result in more $\mathrm{CoP}$ displacement in individuals with knee OA compared to asymptomatic healthy individuals.

\section{Discussion}

\section{Summary of Evidence}

This systematic review synthesized the evidence on the clinical and biomechanical effect of LMV in individuals with knee OA. This review highlighted that the number of published studies and the quality of studies assessed the effect of LMV on pain, stiffness, function, EMG, and knee ROM in individuals with knee OA are limited and generally in weak quality. As a result, we cannot draw any definite conclusion. More studies with a stronger level of evidence are required to evaluate the effects of LMV on people with knee OA.

The WOMAC questionnaire could be used to evaluate pain, stiffness, and physical function in individuals with knee OA (41). All 3 studies on the WOMAC score consistently reported an improvement in pain, stiffness, and physical function following the application of LMV (22, $23,25)$. The previous investigation suggested that gains in clinical and biomechanical parameters following application of the LMV are results of enhanced spinal-mediated reflex activity (42) and cortical excitability (27). The results of our study demonstrate that application of LMV showed the promising effect on clinical outcomes for individuals with knee OA, despite the difference in vibration frequency, duration, and displacement amplitude. The results suggest that the difference in intervention characteristics may have a minimum impact on LMV efficacy on pain, stiffness, and function as long as the vibration frequency is in the range of $10 \mathrm{~Hz}$ to $150 \mathrm{~Hz}$, the displacement amplitude in the range of 0.2 to $1.5 \mathrm{~mm}$, and the duration of application is in range of 1 to 20 minutes. While the risk of bias was generally moderate to high, the results should be interpreted with caution.

The quadriceps weakness is reported in people with knee OA $(43,44)$. Physiotherapy and land-based exercise have been reported to improve muscle strength in people with knee OA, but the presence of pain limits active exercise $(45,46)$. Physical modalities, such as LMV, have been suggested to facilitate physiotherapy interventions to improve muscle activation and strength. The previous study reported that the quadriceps muscle activation level remains elevated for 5 minutes after application of the LMV (13). The controversies in the effect of LMV on muscle strength could be related to the sample of the study and the duration of intervention $(22,26)$. Given the equal vibration duration (20 minutes) $(22,26)$, different followup duration, vibration frequency, vibration force, vibration displacement amplitude, and location of application could explain the controversy among the results. However, it can be suggested that improving muscle performance in individuals with knee OA needs prolonged application of LMV to gain a positive result. In summary, given the limited number of studies that assiessed the effect of LMV on muscle strength, it is unclear which parameters in the LMV application are more decisive to improve muscle function in individuals with knee OA, and further welldesigned studies are required to have a definitive conclusion.

The promising effect of LMV on the improvement of knee ROM was shown for individuals with knee OA (22, $25,40)$. While the limitation of ROM is associated with an increasing level of disability in individuals with knee OA (47), it could be suggested that the application of LMV can lead to a reduced level of disability in individuals with knee OA $(22,25,40)$. However, 3 studies with moderate to high risk of bias are not sufficient to make a conclusive decision regarding the effect of LMV application on knee ROM in individuals with knee OA. These studies provide preliminary evidence to pursue further research.

Application of vibration to tendon or muscle belly may cause the illusion of movement $(48,49)$, or falling when applied to leg muscles in standing position or during walking $(50,51)$. Therefore, the application of LMV may be associated with compensatory strategies for compromised postural control for individuals with knee OA (51). On the other hand, the application of LMV to knee muscles in standing and walking conditions is suggested for the rehabilitation of people with knee OA (27). As a result, evaluating the effect of LMV on postural control has a key role in deciding whether to use LMV in walking/standing conditions for the rehabilitation of people with knee OA.

The available evidence reported no significant change in anterior-posterior displacement of CoP following application of LMV to quadriceps and tibialis anterior muscles. However, increased CoP perturbation was detected following the application of LMV to the triceps surae muscle. These results suggest that the application of LMV to the quadriceps muscle, as the most predictive muscle in the progression of knee OA (52), in standing and walking conditions could be implemented for the rehabilitation of people with knee OA. However, there is only 1 study with a moderate risk of bias available. Thus, caution is needed when interpreting these results.

\section{Limitations}

There are some limitations in this systematic review: First, despite the inclusion of 5 databases to identify the relevant evidence, we may have missed some studies; second, because of the limited number of studies and heterogeneity of study designs, knee OA grades, and the outcomes, we were not able to provide a quantitative synthesize of the evidence; third, limiting this systematic review to studies in the English language excluded evidence in other languages.

\section{Conclusion}

This review revealed the promising effect of LMV on 
pain, stiffness, physical function, and knee ROM improvements for individuals with knee OA. However, this review highlighted a knowledge gap for high-quality evidence on the effect of LMV on clinical and biomechanical outcomes in individuals with knee OA.

\section{Funding}

This study was financially supported by Iran University of Medical Sciences (Grant No. 97-4-15-14030) and the Iranian National Science Foundation (Grant No. 96012164).

\section{Conflict of Interests}

The authors declare that they have no competing interests.

\section{References}

1. Creamer P, Hochberg MC. Osteoarthritis of the knee. Lancet. 1997:350(9087):1328

2. Lawrence RC, Felson DT, Helmick CG, Arnold LM, Choi H, Deyo RA, et al. Estimates of the prevalence of arthritis and other rheumatic conditions in the United States: Part II. Arthritis Rheum. 2008;58(1):26-35

3. Hootman JM, Helmick CG. Projections of US prevalence of arthritis and associated activity limitations. Arthritis Rheum 2006;54(1):226-9.

4. Fisher N, Pendergast D. Reduced muscle function in patients with osteoarthritis. Scand J Rehabil Med. 1997;29(4):213-21.

5. Sharma L, Pai YC. Impaired proprioception and osteoarthritis. Curr Opin Rheumatol. 1997;9(3):253-8.

6.Zhang W, Moskowitz R, Nuki G, Abramson S, Altman R, Arden N, et al. OARSI recommendations for the management of hip and knee osteoarthritis, Part II: OARSI evidence-based, expert consensus guidelines. Osteoarthr Cartil. 2008;16(2):137-62.

7.Zafar H, Alghadir A, Anwer S, Al-Eisa E. Therapeutic effects of whole-body vibration training in knee osteoarthritis: a systematic review and meta-analysis. Arch Phys Med Rehabil. 2015;96(8):152532.

8. Wang P, Yang X, Yang Y, Yang L, Zhou Y, Liu C, et al. Effects of whole body vibration on pain, stiffness and physical functions in patients with knee osteoarthritis: a systematic review and metaanalysis. Clin Rehabil. 2015;29(10):939-51.

9. Anwer S, Alghadir A, Zafar H, Al-Eisa E. Effect of whole body vibration training on quadriceps muscle strength in individuals with knee osteoarthritis: a systematic review and meta-analysis. Physiotherapy. 2016;102(2):145-51.

10. Alghadir A, Anwer S, Zafar H, Iqbal Z. Effect of localised vibration on muscle strength in healthy adults: a systematic review. Physiotherapy. 2017.

11. Abbasi E, Kahrizi S, Razi M, Faghihzadeh S. The Effects of Whole Body Vibration Therapy on Pain, Range of Motion, and Functional Activities Patients with Osteoarthritis of the Knee. J Med Council IRI. 2016;34(2):125-137.

12. Luo J, McNamara BP, Moran K. A portable vibrator for muscle performance enhancement by means of direct muscle tendon stimulation. Med Eng Phys. 2005;27(6):513-22.

13. Pamukoff DN, Ryan ED, Blackburn JT. The acute effects of local muscle vibration frequency on peak torque, rate of torque development, and EMG activity. J Electromyogr Kinesiol. 2014;24(6):888-94.

14. Kurtaiș Y, Öztuna D, Küçükdeveci AA, Kutlay Ș, Hafiz M, Tennant A. Reliability, construct validity and measurement potential of the ICF comprehensive core set for osteoarthritis. BMC Musculoskelet Disord. 2011;12(1):255.

15. WHO. Towards a common language for functioning, disability and health-ICF. WHO Geneva; 2002.

16. Arendt-Nielsen L, Nie H, Laursen MB, Laursen BS, Madeleine P, Simonsen $\mathrm{OH}$, et al. Sensitization in patients with painful knee osteoarthritis. Pain. 2010;149(3):573-81

17. Holla J, Steultjens M, van der Leeden M, Roorda L, Bierma-Zeinstra $\mathrm{S}$, den Broeder A, et al. Determinants of range of joint motion in patients with early symptomatic osteoarthritis of the hip and/or knee: an exploratory study in the CHECK cohort. Osteoarthr Cartil. 2011;19(4):411-9.

18. Shakoor N, Furmanov S, Nelson D, Li Y, Block J. Pain and its relationship with muscle strength and proprioception in knee OA: results of an 8-week home exercise pilot study. J Musculoskelet Neuronal Interact. 2008;8(1):35-42.

19. Aghdam ARM, Kolahi S, Hasankhani H, Behshid M, Varmaziar Z. The relationship between pain and physical function in adults with Knee Osteoarthritis. Int J Sci Basic Appl Res. 2013;4(5):1102-6.

20. Hall M, Hinman RS, van der Esch M, van der Leeden M, Kasza J, Wrigley TV, et al. Is the relationship between increased knee muscle strength and improved physical function following exercise dependent on baseline physical function status? Arthritis Res Ther 2017;19(1):271.

21. Pua YH, Wrigley TV, Collins M, Cowan SM, Bennell KL. Association of physical performance with muscle strength and hip range of motion in hip osteoarthritis. Arthritis Care Res. 2009;61(4):442-50

22. Benedetti MG, Boccia G, Cavazzuti L, Magnani E, Mariani E, Rainoldi A, et al. Localized muscle vibration reverses quadriceps muscle hypotrophy and improves physical function: a clinical and electrophysiological study. Int J Rehabil Res. 2017;40(4):339-46.

23. Rabini A, De Sire A, Marzetti E, Gimigliano R, Ferriero G, Piazzini $\mathrm{DB}$, et al. Effects of focal muscle vibration on physical functioning in patients with knee osteoarthritis: a randomized controlled trial. Eur J Phys Rehabil Med. 2015;51(5):513-20.

24. Shanahan CJ, Wrigley TV, Farrell MJ, Bennell KL, Hodges PW. Postural Response to Vibration of Triceps Surae, but Not Quadriceps Muscles, Differs between People with and without Knee Osteoarthritis. J Orthop Res. 2014;32(8):989-96.

25. Kitay GS, Koren MJ, Helfet DL, Parides MK, Markenson JA. Efficacy of combined local mechanical vibrations, continuous passive motion and thermotherapy in the management of osteoarthritis of the knee. Osteoarthr Cartil. 2009;17(10):1269-74.

26. Rice DA, McNair PJ, Lewis GN. Mechanisms of quadriceps muscle weakness in knee joint osteoarthritis: the effects of prolonged vibration on torque and muscle activation in osteoarthritic and healthy control subjects. Arthritis Res Ther. 2011;13(5):R151.

27. Pamukoff DN, Pietrosimone B, Le:wek MD, Ryan ED, Weinhold PS, Lee DR, et al. Immediate effect of vibratory stimuli on quadriceps function in healthy adults. Muscle Nierve. 2016.

28. Silva HR, Couto BP, Szmuchrowski LA. Effects of mechanical vibration applied in the opposite direction of muscle shortening on maximal isometric strength. J Strength Cond Res. 2008;22(4):1031-6.

29. Dickerson C, Gabler G, Hopper K, Kirk D, McGregor CJ. Immediate effects of localized vibration on hamstring and quadricep muscle performance. Int J Sports Phys Ther.. 2012;7(4):381.

30. Couto B, Silva H, Barbosa M, Szmuchrowski L. Chronic effects of different frequencies of local vibrations. Int $\mathrm{J}$ Sports Med. 2012;33(02):123-9.

31. Couto B, Silva H, da Silveira Neves S, Ramos M, Szmuchrowski L, Barbosa M. Acute effects of resistance training with local vibration. Int J Sports Med. 2013;34(09):814-9.

32. Fattorini L, Ferraresi A, Rodio A, Azzena GB, Filippi GM. Motor performance changes induced by muscle vibration. Eur J Appl Physiol. 2006;98(1):79-87.

33. Pietrangelo T, Mancinelli R, Toniolo L, Cancellara L, Paoli A, Puglielli C, et al. Effects of local vibrations on skeletal muscle trophism in elderly people: Mechanical, cellular, and molecular events. Int J Mol Med. 2009;24(4):503.

34. Iodice P, Bellomo RG, Gialluca G, Fanò G, Saggini R. Acute and cumulative effects of focused high-frequency vibrations on the endocrine system and muscle strength. Eur J Appl Physiol. 2011;111(6):897-904

35. Moher D, Liberati A, Tetzlaff J, Altman DG. Preferred reporting items for systematic reviews and meta-analyses: the PRISMA statement. Ann Intern Med. 2009;151(4):264-9.

36. Kohn MD, Sassoon AA, Fernando ND. Classifications in brief: Kellgren-Lawrence classification of osteoarthritis. Clin Orthop Relat Res. 2016 Aug;474(8):1886-1893.

37. Higgins JP, Sterne JA, Savovic J, Page MJ, Hróbjartsson A, Boutron I, et al. A revised tool for assessing risk of bias in randomized trials. Cochrane Database Syst Rev. 2016;10(Suppl 1):29-31.

38. Sterne JA, Hernán MA, Reeves BC, Savović J, Berkman ND, Viswanathan $\mathrm{M}$, et al. ROBINS-I: a tool for assessing risk of bias in 
non-randomised studies of interventions. BMJ. 2016;355:i4919.

39. Gagnier JJ, Moher D, Boon H, Beyene J, Bombardier C. Investigating clinical heterogeneity in systematic reviews: a methodologic review of guidance in the literature. BMC Med Rese Methodol. 2012;12(1):111.

40. Lievens P, Van de Voorde J. The influence of cycloidal vibrations on the knee joint mobility of osteoarthritic patients. Physiotherapy. 1984;70(6):241-3.

41. McConnell S, Kolopack P, Davis AM. The Western Ontario and McMaster Universities Osteoarthritis Index (WOMAC): a review of its utility and measurement properties. Arthritis Care Res. 2001;45(5):453-61.

42. Burke D, Gandevia S. The human muscle spindle and its fusimotor control. Neural control of movement: Springer; 1995. p. 19-25.

43. Øiestad B, Juhl C, Eitzen I, Thorlund J. Knee extensor muscle weakness is a risk factor for development of knee osteoarthritis. A systematic review and meta-analysis. Osteoarthr Cartil. 2015;23(2):171-7.

44. Bennell KL, Wrigley TV, Hunt MA, Lim B-W, Hinman RS. Update on the role of muscle in the genesis and management of knee osteoarthritis. Rheum Dis Clin. 2013;39(1):145-76.

45. Fransen M, McConnell S, Harmer AR, Van der Esch M, Simic M, Bennell KL. Exercise for osteoarthritis of the knee: a Cochrane systematic review. Br J Sports Med. 2015:bjsports-2015-095424.

46. Collins NJ, Hart HF, Mills KA. Osteoarthritis year in review 2018: rehabilitation and outcomes. Osteoarthr Cartil. 2019;27(3):378-91.

47. Steultjens M, Dekker J, Van Baar M, Oostendorp R, Bijlsma J. Range of joint motion and disability in patients with osteoarthritis of the knee or hip. Rheumatology. 2000;39(9):955-61.

48. Cordo P, Gurfinkel VS, Bevan L, Kerr GK. Proprioceptive consequences of tendon vibration during movement. J Neurobiol. 1995;74(4):1675-88.

49. Courtine G, De Nunzio AM, Schmid M, Beretta MV, Schieppati M. Stance-and locomotion-dependent processing of vibration-induced proprioceptive inflow from multiple muscles in humans. J Neurophysiol. 2007;97(1):772-9.

50. Eklund G. General features of vibration-induced effects on balance. Ups J Med Sci. 1972;77(2):112-24.

51. Ivanenko Y, Solopova I, Levik Y. The direction of postural instability affects postural reactions to ankle muscle vibration in humans. Neurosci Lett. 2000;292(2):103-6.

52. Segal NA, Glass NA, Torner J, Yang M, Felson DT, Sharma L, et al. Quadriceps weakness predicts risk for knee joint space narrowing in women in the MOST cohort. Osteoarthr Cartil. 2010;18(6):769-75. 